Article

\title{
Solid-State Nuclear Magnetic Resonance (NMR) and Nuclear Magnetic Relaxation Time Analyses of Molecular Mobility and Compatibility of Plasticized Polyhydroxyalkanoates (PHA) Copolymers
}

\author{
Masakazu Nishida ${ }^{1, *(1)}$, Tomoko Tanaka ${ }^{1}$, Yoshio Hayakawa ${ }^{1}$ and Masahiro Nishida ${ }^{2}$ \\ 1 National Institute of Advanced Industrial Science and Technology (AIST), Shimoshidami 2266-98, \\ Moriyama-ku, Nagoya 463-8560, Japan; tomo.tanaka@aist.go.jp (T.T.); hayakawa-y@aist.go.jp (Y.H.) \\ 2 Nagoya Institute of Technology, Gokiso-cho, Showa-ku, Nagoya, Aichi 466-8555, Japan; \\ nishida.masahiro@nitech.ac.jp \\ * Correspondence: m-nishida@aist.go.jp; Tel.: +81-52-736-7493
}

Received: 19 April 2018; Accepted: 5 May 2018; Published: 7 May 2018

\begin{abstract}
The molecular mobility and compatibility of plasticized polyhydroxyalkanoates (PHA) were investigated, focusing on changes due to copolymerization using either flexible poly (butylene succinate) (PBS) or rigid poly(lactic acid) (PLA) units. For the case of a poly(3-hydroxybutyrate) (PHB) unit in plasticized PHA, copolymerization of either PBS or PLA decreased ${ }^{1} \mathrm{H}$ and ${ }^{13} \mathrm{C}$ spin-lattice relaxation times in the laboratory frame $\left(T_{1} \mathrm{H}\right.$ and $\left.T_{1} \mathrm{C}\right)$ in the same manner, while PBS produced a lower ${ }^{1} \mathrm{H}$ spin-lattice relaxation time in the rotating frame $\left(T_{1 \rho} \mathrm{H}\right)$ than PLA. Both the signals of ${ }^{1} \mathrm{H}$ MAS (magic-angle spinning) and ${ }^{13} \mathrm{C}$ PST (pulse saturation transfer) MAS nuclear magnetic resonance (NMR) spectra were sharpened and increased by copolymerization with PBS. A variable temperature relaxation time analysis showed that the decrease of $T_{1} \mathrm{H}$ values was dominated by the ${ }^{1} \mathrm{H}$ spin diffusion via the interface between $\mathrm{PHB}$ and the added polyester because of the good compatibility. Meanwhile, the decrease of $T_{1} \mathrm{C}$ values was dominated by increasingly rapid molecular motions of PHB because of the lowered crystallinity due to the plasticization. Slow molecular motions ( $\mathrm{kHz}$ order) were enhanced more by the addition of PBS than PLA, although rapid molecular motions (MHz order) were enhanced by either polyester. Several NMR parameters were beneficial for analyzing the manufacturing process as the indexes of polymer compatibility and molecular motions.
\end{abstract}

Keywords: inedible biomass; polyester; copolymerization; plasticization; solid-state nuclear magnetic resonance (NMR); nuclear magnetic relaxation; variable temperature measurement

\section{Introduction}

For the development of a post-petroleum society, recycling resources from biomass is a high priority. Poly(lactic acid) (PLA) is the most popular biomass-based polymer and is used for daily necessities; however, there is a problem of food security because of the use of edible starch as a main raw material. As one solution to this problem, polyhydroxyalkanoates (PHA) have attracted attention as a biomass-based polymer made from non-edible materials. PHA is the generic name for a biopolyester family, consisting of the following polymers, poly(3-hydroxybutylate) (PHB) and poly(3-hydroxyvalerate) (PHV), including their isomeric polymers and co-polymers; the characteristic properties of PHA resulting from the chain length and composition could be tuned to various industrial applications [1]. Microbial production is the most commonly used method for supplying PHA; not only carbohydrates but also fatty acids were used as the carbon source depending on the bacterial strain employed [2-4]. For mechanical applications, crystal structures and crystallization kinetics have 
been studied in connection with biosynthesis and the polymerization mechanism [5]. Furthermore, PHA is expected to be useful in the medical field because of its biodegradability and biocompatibility; the improvement of solubility of PHA in water was studied by modification of the polymer chain [6]. However, PHA has limitations in its thermal and physical properties, such as low processability, brittleness, hydrophilicity and inferior biocompatibility; plasticizers and plasticization processes were studied to resolve these limitations [7].

In order to improve the processability and brittleness of PHA, modifications of PHB and PHB-based polymers have been intensively studied as follows. Modification of PHB with plasticizers and other copolymers as the improvement method was analyzed with differential scanning calorimetry (DSC), thermogravimetric analysis (TG), and a melt flow indexer [8]. Biobased epoxidized broccoli oil can plasticize and stabilize PHA and its plasticization process was characterized by several instrumental analyses [9]. Copolymerization and blending for PHB and PHB-based polymers is a promising method for improving their material properties. For example, the material properties and processing options of PHB was improved using reactive melt processing of PHB and PLA via peroxide-induced cross-linking [10]. Chemical compatibilization using dicumyl peroxide could also ameliorate the mechanical properties, such as tensile strength, impact toughness, and elongation at break, of blends of PHB and PHB-PHV copolymers with poly(butylene succinate) (PBS) [11]. Impact properties were improved by melt extrusion and subsequent injection molding of a $\mathrm{PHB} /$ poly ( $\varepsilon$-caprolactone) (PCL) blend, which was characterized by DSC, TG, and field emission scanning electron microscopy (FESEM) [12]. Injection molding could also provide biocomposites based on PHB/PHV copolymers and lignocellulosic filler together with blow extrusion [13]. For packaging applications, blends of PHB/PHV copolymer and PLA were studied, focusing on their mechanical and barrier properties [14]. Tensile properties of PHA blends were significantly affected by their PCL content; the mechanism of interaction was analyzed by rheo-optical near-infrared (NIR) spectroscopy [15].

Solid-state nuclear magnetic resonance (NMR) is an extremely useful analytical method to obtain information about chemical behaviors and molecular dynamics. The molecular dynamics of amorphous and crystalline PHB were analyzed with ${ }^{13} \mathrm{C}$ magic-angle spinning (MAS) NMR and ${ }^{13} \mathrm{C}$ spin-lattice relaxation times $\left(T_{1} C\right)$ [16]. A solid-state NMR study of bacterial PHB-based copolyesters was performed using three ${ }^{13} \mathrm{C}$ MAS NMR methods, cross-polarization (CP), dipolar decoupling (DD), and pulse saturation transfer (PST), as well as variable contact times in ${ }^{13} \mathrm{C} C \mathrm{CP}-\mathrm{MAS}$ NMR [17]. Semi-crystalline PHB and PHB-PHV copolymer were studied by several solid-state NMR spectral and relaxation time analyses to reveal the domain structure and mobility [18]. Reinforcement of PHA with cross-linked cellulose acetate was monitored by solid-state ${ }^{13} \mathrm{C}$ NMR [19]. Time-domain nuclear magnetic resonance (TD-NMR) was also useful for determining the morphology of PHB/PCL blends [20]. Very recently, plasticized PLA/PHA polymer blends were studied by single-pulse NMR and $T_{1} C[21]$.

As an example of the use of solid-state NMR for analyzing the mechanical properties of biomass-based polymers, we have already studied PLA fibers produced by an extrusion process to reveal the correlation between tensile properties and spin-lattice relaxation time in PLA/PCL copolymer fibers [22], the morphological changes of PLA/organic composite fibers [23], and the effects of nucleating and plasticization in drawn PLA fibers during degradation [24]. In addition, using relaxation time analyses as a possible method of quality control of biomass-based materials, we have also revealed the interaction of water molecules with phenol formaldehyde resin-impregnated soft wood [25], that with biomass constituent in Japanese cypress [26], and that with superheated steam-treated plant materials [27]. On the basis of our previous solid-state NMR and relaxation time studies of the biomass-based materials, the present study is intended to clarify the information necessary for improvements to the processability and brittleness of PHA. At first, focusing on two kinds of plasticized PHA copolymers including PBS and PLA, we measure not only their ${ }^{13} \mathrm{C} C \mathrm{CP}-\mathrm{MAS}$ and ${ }^{13} \mathrm{C}$ PST-MAS NMR spectra but also three spin-lattice relaxation times, $T_{1} \mathrm{H}, T_{1} \mathrm{C}$, and $T_{1 \rho} \mathrm{H}$, 
at ambient temperature to show the effects on these spectra and parameters of these added polyesters. Next, by combining the results at ambient temperature with additional ${ }^{1} \mathrm{H}$ MAS NMR, $T_{1} \mathrm{H}$, and $T_{1} \mathrm{C}$ measurements at variable temperatures, we will reveal how the modification of the added polyesters affects the molecular mobility and the chemical compatibility between the polymer constituents.

\section{Materials and Methods}

\subsection{Materials}

Pre-plasticized PHB pellets were purchased from Biomer, Krailling, Germany. PBS pellets were purchased from Showa Highpolymer Co. Ltd., Tokyo, Japan. PLA pellets were purchased from Mitsui Chemical Co. Ltd., Tokyo, Japan. The following two kinds of plasticized PHA pellet used for the present study were purchased from G5 Manufacturing, Singapore. The PHA4422P pellet consisted of 65\% PHA, 30\% PBS, and 5\% crosslinking reagent and the catalog specification values of PHA4422P were as follows: melt flow rate: $2.5 \mathrm{~g} / 10 \mathrm{~min}$; tensile strength: $21 \mathrm{MPa}$; elongation: $600 \%$; Izod impact strength: $\geq 30 \mathrm{~kJ} / \mathrm{m}^{2}$; flexural modulus: $600 \mathrm{MPa}$. The PHA5533L pellet consisted of $60 \%$ PHA, $35 \%$ PLA, and 5\% crosslinking reagent and the catalog specification values of PHA5533L were as follows: melt flow rate: $4.0 \mathrm{~g} / 10 \mathrm{~min}$; tensile strength: $18 \mathrm{MPa}$; elongation: $100 \%$; Izod impact strength: $22 \mathrm{~kJ} / \mathrm{m}^{2}$; flexural modulus: $1000 \mathrm{MPa}$. All materials were used without further purification.

\subsection{Differential Scanning Calorimetry (DSC)}

Differential scanning calorimetry (DSC) was performed on a DSC-60 instrument (Shimadzu Co. Ltd., Kyoto, Japan). The sample (30 mg) was sealed in an aluminum pan and then was heated from 30 to $250{ }^{\circ} \mathrm{C}$ at a heating rate of $10{ }^{\circ} \mathrm{C} / \mathrm{min}$ under $250 \mathrm{~mL} / \mathrm{min} \mathrm{N}_{2}$ flow. An empty aluminum pas was used as a reference.

\subsection{X-ray Diffraction (XRD)}

The crushed sample was placed on a sample holder and then the X-ray diffraction (XRD) under $\mathrm{Cu} \mathrm{K} \alpha$ irradiation was measured on a RINT-Ultima II diffratometer (Rigaku Co. Ltd., Tokyo, Japan). The diffratometer was operating at $40 \mathrm{kV}$ and $40 \mathrm{~mA}$ and the diffractogram was recorded at $2 \theta$ angles between $5^{\circ}$ and $40^{\circ}$.

\subsection{Nuclear Magnetic Resonance (NMR) Measurements at Ambient Temperature}

Solution nuclear magnetic resonance (NMR) spectra were measured on a Varian INOVA-300 (Palo Alto, CA, USA) with a Varian $5 \mathrm{~mm}$ four-nucleus auto-NMR triple-resonance liquid probe in $\mathrm{CDCl}_{3}$ as a solvent. ${ }^{1} \mathrm{H}$ NMR spectra were collected at $299.95 \mathrm{MHz}$ with a $7.0 \mu \mathrm{s} \pi / 2$ pulse for the ${ }^{1} \mathrm{H}$ nuclei and $3.74 \mathrm{~s}$ acquisition period over a $4.5 \mathrm{kHz}$ spectra width with $1.2 \mathrm{~s}$ recycle delay in 16-128 transients. ${ }^{13} \mathrm{C}$ NMR spectra were collected at $75.43 \mathrm{MHz}$ with a $6.5 \mu \mathrm{s} \pi / 2$ pulse for the ${ }^{13} \mathrm{C}$ nuclei and $1.82 \mathrm{~s}$ acquisition period over a $16.5 \mathrm{kHz}$ spectra width with $1.19 \mathrm{~s}$ recycle delay in 2048-15,000 transients.

Solid-state NMR spectra were measured on a Varian 400 NMR system spectrometer (Palo Alto, CA, USA) with a Varian $4 \mathrm{~mm}$ double-resonance T3 solid probe. The samples were placed in a $4 \mathrm{~mm} \mathrm{ZrO}_{2}$ rotor spun at $15 \mathrm{kHz}$ over a temperature range of $20-22{ }^{\circ} \mathrm{C}$. Solid-state ${ }^{13} \mathrm{C}$ MAS NMR spectra were measured at $100.56 \mathrm{MHz}$ for the ${ }^{13} \mathrm{C}$ nuclei and were collected with a $40 \mathrm{~ms}$ acquisition period over a $30.7 \mathrm{kHz}$ spectral width in 1024-2048 transients. Proton decoupling was performed with an $86 \mathrm{kHz}$ ${ }^{1} \mathrm{H}$ decoupling radio frequency with a small phase incremental alteration (SPINAL) decoupling pulse sequence. The cross polarization and magic angle spinning (CP-MAS) NMR spectra were measured with a $5.0 \mathrm{~s}$ recycle delay using a ramped-amplitude pulse sequence with a 2 ms contact time and a $2.5 \mu \mathrm{s} \pi / 2$ pulse for the ${ }^{1} \mathrm{H}$ nuclei. The amplitude of the ${ }^{1} \mathrm{H}$ nuclei was ramped up linearly from $90.5 \%$ of its final value during the cross-polarization contact time. The pulse saturation transfer and magic 
angle spinning (PST-MAS) NMR spectra were measured with a $2.6 \mu \mathrm{s} \pi / 2$ pulse for the ${ }^{13} \mathrm{C}$ nuclei with a $5 \mathrm{~s}$ recycle delay after saturation of ${ }^{1} \mathrm{H}$ nuclei with 13 consecutive $2.5 \mu$ s pulses and a $27.5 \mu$ s delay.

\subsection{Nuclear Magnetic Relaxation Time Analyses}

The ${ }^{1} \mathrm{H}$ spin-lattice relaxation time in the laboratory frame $\left(T_{1} \mathrm{H}\right)$ was indirectly measured via detection of ${ }^{13} \mathrm{C}$ resonance enhanced by cross-polarization, applied after a $\pi$ pulse to ${ }^{1} \mathrm{H}$ nuclei with the inversion recovery method. The ${ }^{13} \mathrm{C}$ spin-lattice relaxation time in the laboratory frame $\left(T_{1} \mathrm{C}\right)$ was measured with the conventional Torchia's pulse sequence [28]. The ${ }^{1} \mathrm{H}$ spin-lattice relaxation time in the rotating frame $\left(T_{1 \rho} \mathrm{H}\right)$ was indirectly measured via detection of ${ }^{13} \mathrm{C}$ resonance enhanced by cross-polarization applied after a $\pi / 2-\tau$-spin lock pulse ( $86 \mathrm{kHz}$ of radio frequency) with variable spin lock times over a range of 100-8000 $\mu$ s. The relaxation time analyses were performed with the same solid-state probe with the same contact time and acquisition period used for the ${ }^{13} \mathrm{C} \mathrm{CP}-\mathrm{MAS}$ NMR spectrum.

\subsection{Variable Temperature Solid-State NMR and Relaxation Time Measurements}

Variable temperature solid-state NMR spectra and relaxation times were also measured on the same spectrometer and probe as the ambient temperature measurements. Low-temperature measurement was started at a low temperature side of $-40^{\circ} \mathrm{C}$ and the temperature increased to $10^{\circ} \mathrm{C}$. High-temperature measurement was started at a low temperature side of $30^{\circ} \mathrm{C}$ and heating to $50{ }^{\circ} \mathrm{C}$. One step of heating consisted of $10{ }^{\circ} \mathrm{C}\left({ }^{1} \mathrm{H}\right.$ MAS NMR, $T_{1} \mathrm{H}, T_{1} \mathrm{C}$ high temperature $)$ or $20{ }^{\circ} \mathrm{C}\left(T_{1} \mathrm{C}\right.$ low temperature). The samples were placed in a $4 \mathrm{~mm} \mathrm{ZrO}_{2}$ rotor spun at $12 \mathrm{kHz}$ (low temperature) and $15 \mathrm{kHz}$ (high temperature) under nitrogen flow. Low temperature ${ }^{1} \mathrm{H}$ MAS NMR spectra were measured at $399.88 \mathrm{MHz}$ for the ${ }^{1} \mathrm{H}$ nuclei and were collected with a $2.9 \mu \mathrm{s} \pi / 2$ pulse for the ${ }^{1} \mathrm{H}$ nuclei and $20 \mathrm{~ms}$ acquisition period over a $30.5 \mathrm{kHz}$ spectral width in 4 transients, and a $3 \mathrm{~s}$ recycle delay. Low and high temperature $T_{1} \mathrm{H}$ and $T_{1} \mathrm{C}$ were measured using the same acquisition parameters as described above. Each low and high temperature measurement was performed independently because it was difficult to control low temperature for a long time due to the use for liquid nitrogen.

\section{Results and Discussion}

\subsection{Polymer Properties of Plasticized Polyhydroxyalkanoates (PHA) Pellets}

The pre-plasticized PHB pellet showed poor processability because of stiffness and low solubility. Copolymerization with the biodegradable polyesters, PBS and PLA, improved the mechanical properties of PHA. According to the catalog specification values, copolymerization with PBS increased elongation and Izod impact strength, while copolymerization with PLA increased melt flow rate and flexural modulus. Actually, when installing a sample into the solid-state NMR rotor, the pre-plasticized PHB was difficult to cut and/or crush, even though the plasticized PHA copolymers were easily deformable to prepare a solid-state NMR sample.

In order to determine in detail the constituents of the plasticized PHA pellets connected with the mechanical properties, solution NMR spectra were measured in $\mathrm{CDCl}_{3}$. Figure 1a shows ${ }^{1} \mathrm{H} N M R$ spectra of the pre-plasticized PHB and the plasticized PHA pellets. The PHA4422P pellet (3) showed three PHB signals, doublet $\left(\mathrm{CH}_{3}, 1.28 \mathrm{ppm}\right)$, quartet-doublet $\left(\mathrm{CH}_{2}, 5.24 \mathrm{ppm}\right)$, and quartet $(\mathrm{CH}, 5.26 \mathrm{ppm})$, which can be also observed for the original PHB (1). PHA4422P also had small amount of poly(4-hydrobutyrate) (P4HB) [29], and the added PBS for the copolymerization. One can see a trace peak at $0.98 \mathrm{ppm}$, in which region a $\mathrm{CH}_{3}$ group of $\mathrm{PHA}$ having long alkyl groups might appear; however, the actual structure could not be assigned at this time. Meanwhile, ${ }^{1} \mathrm{H}$ NMR spectra also indicated that the PHA5533L pellet (4) consisted of PHB, the added PLA, and a small amount of PBS and P4HB. Minor constituents in each pellet could be confirmed by ${ }^{13} \mathrm{C}$ NMR spectra (Figure $1 \mathrm{~b}$ ). The signals of P4HB in both PHA4422P (3) and PHA5533L (4) also appeared not only in the aliphatic region but also in the carbonyl region. 


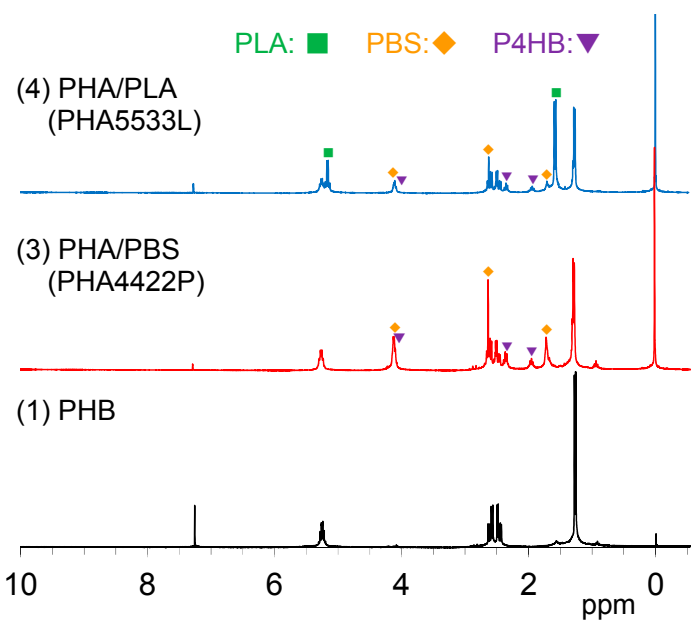

(a) ${ }^{1} \mathrm{H}$ NMR
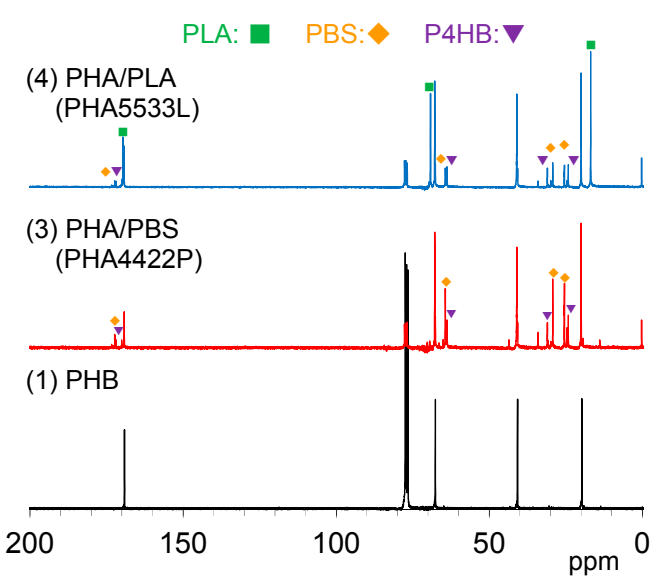

(b) ${ }^{13} \mathrm{C}$ NMR

Figure 1. Solution nuclear magnetic resonance (NMR) spectra of plasticized polyhydroxyalkanoates (PHA) copolymers and original poly(3-hydroxybutyrate) (PHB) in $\mathrm{CDCl}_{3}$.

The improvement of mechanical properties due to the copolymerization with the biodegradable polyesters could be explained by a change of thermal characteristics. Figure 2 shows the DSC curves for the modified PHA pellets and the reference polymers. The melting peak $\left(T_{\mathrm{m}}\right)$ of the original PHB (1) appeared at a relatively high temperature $\left(174^{\circ} \mathrm{C}\right)$ with no other endothermic and exothermic peaks. Of the constituent polyesters used for the copolymerization, PBS (2) had a lower $T_{\mathrm{m}}\left(112{ }^{\circ} \mathrm{C}\right)$ while PLA (5) also had a high $T_{\mathrm{m}}\left(171^{\circ} \mathrm{C}\right)$. Interestingly, the copolymerization resulted in a decrease of $T_{\mathrm{m}}$ to a value lower than the initial $T_{\mathrm{m}}$ of the constituent polyesters, although the heat capacities of both plasticized PHA pellets were smaller than the original PHB. The PHA4422P pellet (3) had a lower $T_{\mathrm{m}}\left(89^{\circ} \mathrm{C}\right)$ with higher temperature small endothermic peaks. In contrast, the PHA5533L pellet (4) had a glass transition peak with relaxation $\left(T_{\mathrm{g}}: 64^{\circ} \mathrm{C}\right)$ and cold crystallization $\left(T_{\mathrm{cc}}: 95^{\circ} \mathrm{C}\right)$, and a quite high $T_{\mathrm{m}}\left(150^{\circ} \mathrm{C}\right)$. Considering the DSC results together with the solution NMR, small amounts of P4HB and PBS were extremely effective for changing the thermal properties of the PHA5533L pellet. Moreover, the DSC results showed that the plasticization of PHA improved processability because of the decrease of $T_{\mathrm{m}}$ (PBS) or $T_{\mathrm{g}}$ (PLA).

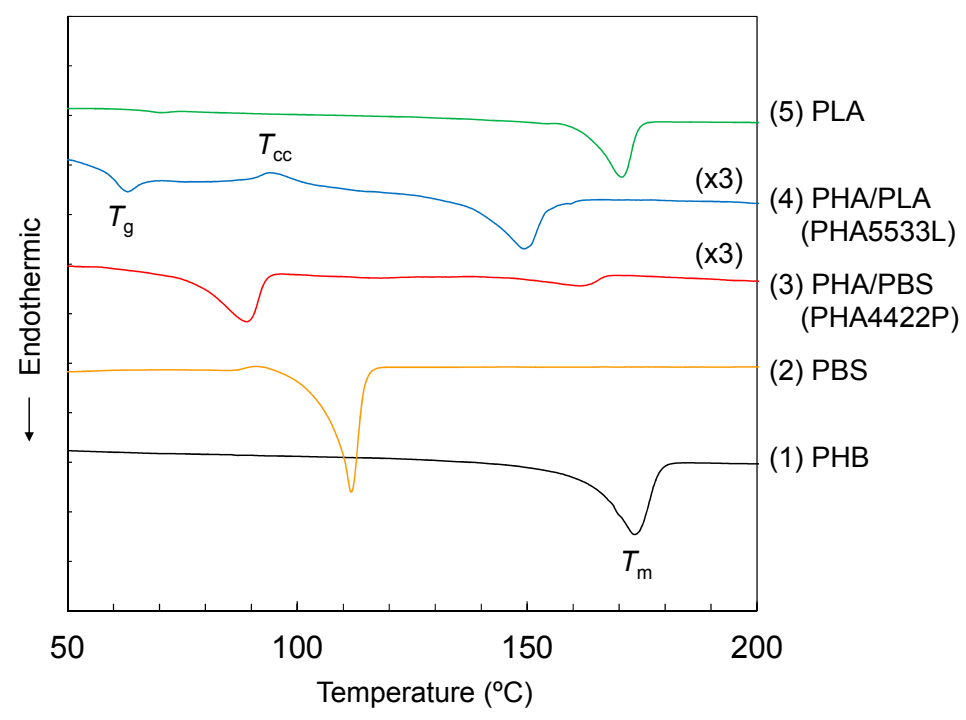

Figure 2. Differential scanning calorimetry (DSC) heating curves of plasticized PHA copolymers and constituent polymers. 
The copolymerization with the biodegradable polyesters also changed the crystallinity of the PHA. Figure 3 shows changes in the XRD patterns of PHA by the addition of other polyesters. The original PHB (1) had moderate crystallinity, showing orthorhombic crystal planes with major sharp peaks at $2 \theta=13.5^{\circ}(020)$ and $16.9^{\circ}$ (110). After the copolymerization of PHA with PBS [PHA4422P (3)], new peaks that originated from PBS appeared at $2 \theta=19.6^{\circ}(020)$ and $22.6^{\circ}(110)$ overlapped with the (021) and (111) peaks of PBS [30]. At the same time, the amorphous peak of PHA clearly increased. The copolymerization of PHA with PLA [PHA5533L (4)] increased further the amorphous peak of PHA; only a small peak of PLA was observed at $2 \theta=16.4^{\circ}$ (100) [24]. In both cases of PHA4422P and PHA5533L, characteristic XRD peaks from P4HB could not be assigned. The XRD results showed that the copolymerization of both biodegradable polymers decreased the crystallinity of PHA and that the decrease was more pronounced for the copolymerization with PLA than with PBS.

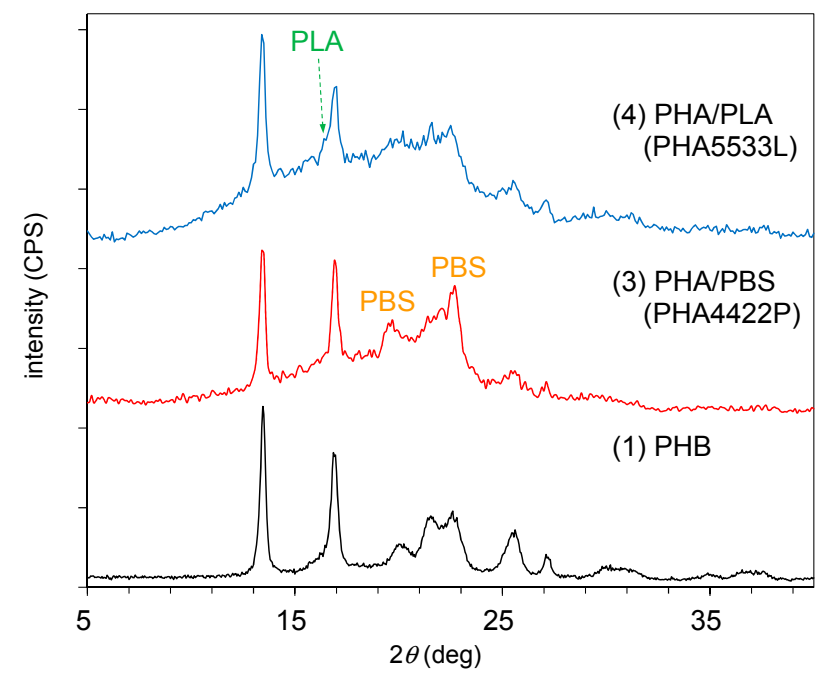

Figure 3. X-ray diffraction (XRD) patterns of plasticized PHA copolymers and original PHB.

\section{2. ${ }^{13}$ C Magic-Angle Spinning (MAS) NMR of Plasticized PHA Copolymers and Constituent Polymers}

Solid-state ${ }^{13} \mathrm{C}$ NMR is a powerful tool for analyzing the crystallinity and mobility of polymer chains. The ${ }^{13} \mathrm{C}$ CP-MAS NMR variant is commonly used in polymer science; it utilizes the magnetization transfer from ${ }^{1} \mathrm{H}$ nuclei to ${ }^{13} \mathrm{C}$ nuclei, enhancing the signal of a rigid substituent. Figure 4a shows ${ }^{13} \mathrm{C} C$ P-MAS NMR spectra of plasticized PHA copolymers and constituent polymers. Each signal for the polymer constituents, PHB (1), PBS (2) and PLA (5) could be effectively detected

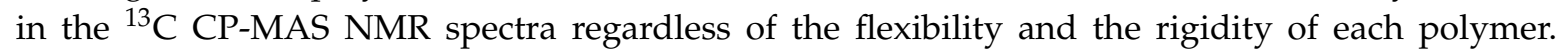
The ${ }^{13} \mathrm{C}$ CP-MAS signals of the plasticized PHA4422P (3) could be assigned as PHB and PBS, while those of the plasticized PHA5533L (4) as PHB, PLA, and PBS. The isomeric polymer P4HB could be also detected in both PHA4422P (3) and PHA5533L (4).

Meanwhile, ${ }^{13} \mathrm{C}$ PST-MAS NMR is a method utilizing the nuclear Overhauser effect, resulting in the enhancement of a signal of a substituent having high mobility near a hydrogen atom [27]. Figure $4 \mathrm{~b}$ shows ${ }^{13} \mathrm{C}$ PST-MAS NMR spectra of plasticized PHA copolymers and constituent polymers. Actually, the $\mathrm{CH}_{3}$ group of PLA (5) and the $\mathrm{OCH}_{2} \mathrm{CH}_{2}$ group of PBS (2) showed larger intensities than other substituents because the amplitudes of their molecular motions were higher. For the pre-plasticized $\mathrm{PHB}(1)$, the $\mathrm{CH}_{3}$ group had a high signal intensity compared to the other signals. Interestingly, the copolymerization of PHA with PBS [PHA4422P (3)] increased the signal from $\mathrm{CH}_{2}$ and $\mathrm{CH}_{3}$ groups accompanied by the appearance of signals from the minor isomeric polymer P4HB. In both PHA (1) and PHA4422P (3), trace signals appeared at the higher field near the $\mathrm{CH}_{3}$ groups' signal. These small signals originated from trace amounts of PHA having long alkyl groups. In contrast, the copolymerization of PHA with PLA [PHA5533L (4)] did not increase the $\mathrm{CH}_{2}$ and $\mathrm{CH}_{3}$ 
groups' signals but only gave the sum of the signals of PHA, P4HB, PLA, and PBS. The results of the ${ }^{13} \mathrm{C}$ PST-MAS NMR spectra confirmed that PBS enhanced molecular mobility of the whole copolymer system. Next, we consider the different trends in molecular mobility between the plasticization with PBS [PHA4422P (3)] and PLA [PHA5533L (4)] revealed by their spin-lattice relaxation times.

(5) PLA

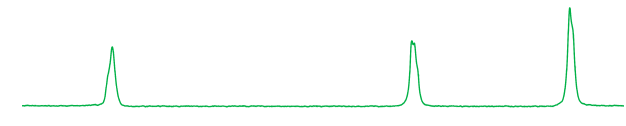

(4) PHA/PLA

(PHA5533L)

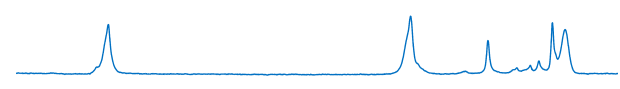

(3) PHA/PBS

(PHA4422P)

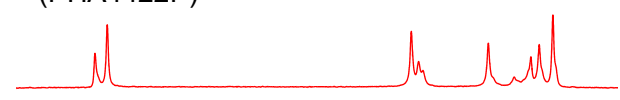

(2) PBS
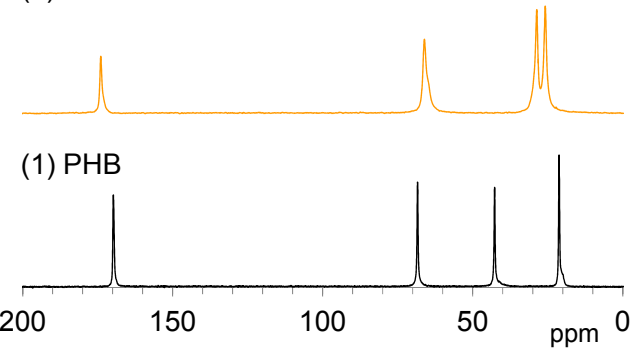

(a) ${ }^{13} \mathrm{C}$ CP-MAS NMR
(5) PLA

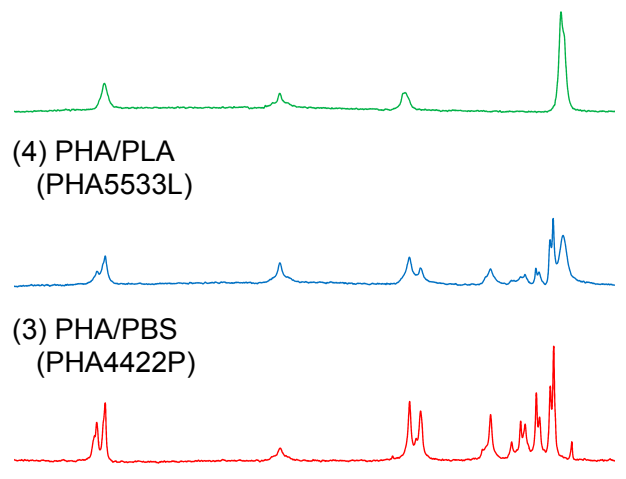

(2) PBS

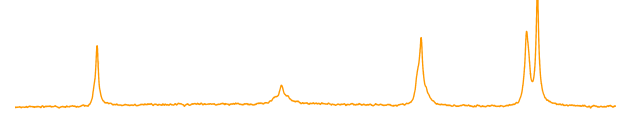

(1) PHB

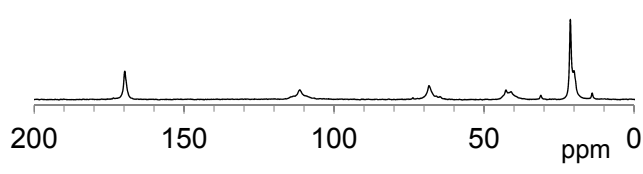

(b) ${ }^{13} \mathrm{C}$ PST-MAS NMR

Figure 4. ${ }^{13} \mathrm{C}$ Magic-angle spinning (MAS) NMR spectra of plasticized PHA copolymers and constituent polymers.

\subsection{Spin-Lattice Relaxation Times in the Laboratory Frame of Plasticized PHA Copolymers and Constituent Polymers}

The ${ }^{1} \mathrm{H}$ spin-lattice relaxation time in the laboratory frame $\left(T_{1} \mathrm{H}\right)$ is reduced by rapid molecular motions matched to the Larmor frequency. For example, the ${ }^{1} \mathrm{H}$ spin-lattice relaxation in the laboratory frame ( $T_{1} \mathrm{H}$ relaxation) of PLA is promoted by the rotation of a $\mathrm{CH}_{3}$ group around its $\mathrm{C}_{3}$ axis. Moreover, the $T_{1} \mathrm{H}$ value of each substituent in the same polymer chain adopts an averaged value because of ${ }^{1} \mathrm{H}$ spin diffusion.

Figure 5a shows $T_{1} \mathrm{H}$ values of plasticized PHA copolymers and constituent polymers. As described in the above paragraph, the $T_{1} \mathrm{H}$ values of PLA (5) were averaged by the spin diffusion to have almost the same values $(1.1 \mathrm{~s})$ due to the $T_{1} \mathrm{H}$ relaxation via the rotation of the $\mathrm{CH}_{3}$ group. Although the $T_{1} \mathrm{H}$ values of PBS (2) also showed averaged values (1.2 s) similar to PLA, the $T_{1} \mathrm{H}$ relaxation of PBS cannot be explained directly by molecular motions of a specific substituent, such as a $\mathrm{CH}_{3}$ group. Moreover, the $T_{1} \mathrm{H}$ values of PHB (1) had longer averaged values (2.0 s) even though the $T_{1} \mathrm{H}$ relaxation occurred via the motion of $\mathrm{CH}_{3}$ group. The different $T_{1} \mathrm{H}$ values of PLA (5) and PHB (1) having the same $T_{1} \mathrm{H}$ relaxation route were due to whether the frequency of $\mathrm{CH}_{3}$ motion matched the Larmor frequency, or not.

Copolymerization with the biodegradable polyesters significantly decreased the $T_{1} \mathrm{H}$ values of PHB. For the plasticized PHA4422P (3) in particular, the addition of PBS decreased not only the $T_{1} \mathrm{H}$ values of the PHB unit $(1.0 \mathrm{~s})$ but also the $T_{1} \mathrm{H}$ values of the PBS unit $(0.9 \mathrm{~s})$. Meanwhile, for the plasticized PHA5533L (4), the addition of PLA also decreased the $T_{1} \mathrm{H}$ values of the PHB unit $(1.2 \mathrm{~s})$, 
although the $T_{1} \mathrm{H}$ values of the PLA unit kept the original values of the PLA pellet (1.05 s). At the same time, the $T_{1} \mathrm{H}$ values of trace amounts of the PBS unit slightly decreased (1.0 s) in PHA5533L. These $T_{1} \mathrm{H}$ reductions were caused by the enhancement of the $T_{1} \mathrm{H}$ relaxation due to the heterogeneity that arose from the amorphous moiety, as we have previously described for PLA copolymer fibers [24].

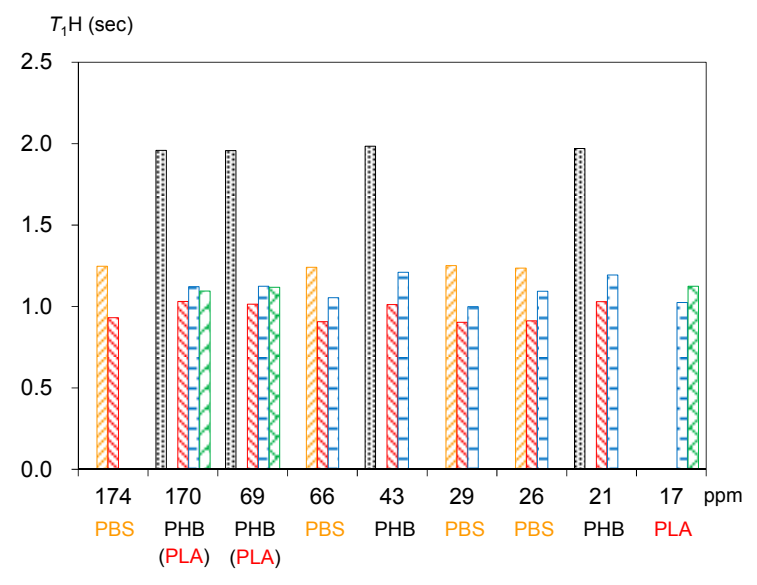

(a) $T_{1} \mathrm{H}$

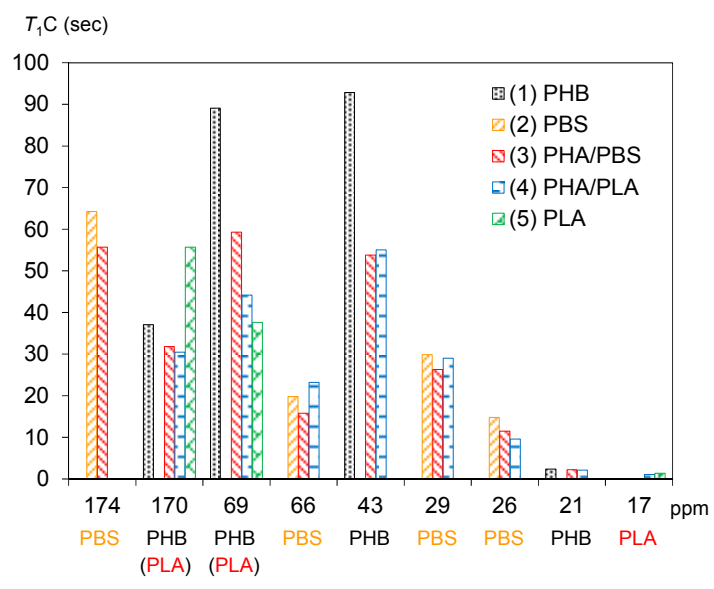

(b) $T_{1} \mathrm{C}$

Figure 5. Changes of $T_{1} \mathrm{H}$ and $T_{1} \mathrm{C}$ values with copolymerization. The horizontal axis shows the chemical shift of each signal appearing in the ${ }^{13} \mathrm{C}$ cross-polarization (CP) MAS NMR spectra while the vertical axis shows the corresponding $T_{1} \mathrm{H}(\mathbf{a})$ and $T_{1} \mathrm{C}(\mathbf{b})$ values.

The ${ }^{13} \mathrm{C}$ spin-lattice relaxation time in the laboratory frame $\left(T_{1} \mathrm{C}\right)$ can provide information on molecular motions for each substituent more directly because it excludes the effect of ${ }^{1} \mathrm{H}$ spin diffusion. Figure $5 \mathrm{~b}$ shows $T_{1} \mathrm{C}$ values of plasticized PHA copolymers and constituent polymers. One can see a different $T_{1} \mathrm{C}$ value for each substituent in the pre-plasticized PHB (1): $\mathrm{C}=\mathrm{O}, 37 \mathrm{~s} ; \mathrm{CH}, 89 \mathrm{~s} ; \mathrm{CH}_{2}$, $92 \mathrm{~s} ; \mathrm{CH}_{3}, 2.4 \mathrm{~s}$. The $T_{1} \mathrm{C}$ value of $\mathrm{CH}_{3}$ nearly equaled the $T_{1} \mathrm{H}(2.0 \mathrm{~s})$ value because the ${ }^{13} \mathrm{C}$ spin-lattice relaxation ( $T_{1} \mathrm{C}$ relaxation) was also promoted by the $\mathrm{CH}_{3}$ rotation, the same as for the $T_{1} \mathrm{H}$ relaxation. This closeness between the $T_{1} \mathrm{C}$ relaxation of $\mathrm{CH}_{3}$ and the $T_{1} \mathrm{H}$ due to the $\mathrm{CH}_{3}$ rotation also arose in PLA (5) $\left(T_{1} \mathrm{C}, 1.4 \mathrm{~s} ; T_{1} \mathrm{H}, 1.1\right)$; however, the $\mathrm{C}=\mathrm{O}$ group $(56 \mathrm{~s})$ showed a longer value than the $\mathrm{CH}$ group (38 s) in PLA, unlike the pre-plasticized PHB. One can also see the longer $T_{1} C$ value of the $C=O$ group (64 s) and moderate $T_{1} \mathrm{C}$ values of $\mathrm{CH}_{2}$ groups (15-30 s) in PBS (2). Although PBS had high flexibility, the molecular motion of each substituent did not match with the Larmor frequency of the ${ }^{13} \mathrm{C}$ nuclei.

The reduction of $T_{1} \mathrm{C}$ values due to the copolymerization was also observed not only in PHA4422P (3) but also in PHA5533L (4), similarly to the $T_{1} \mathrm{H}$ values. The $T_{1} \mathrm{C}$ reduction of the PHB unit was significant for $\mathrm{C}(=\mathrm{O}) \mathrm{CH}_{2}$ [original $89 \mathrm{~s}$; 4422(PBS), $59 \mathrm{~s}$; 5533(PLA), $44 \mathrm{~s}$ ] and $\mathrm{OCH}_{2}$ [original, $93 \mathrm{~s}$; 4422(PBS), $54 \mathrm{~s}$; 5533(PLA), $55 \mathrm{~s}]$. In contrast, the $T_{1} \mathrm{C}$ value of the $\mathrm{C}=\mathrm{O}$ of the $\mathrm{PBS}$ unit changed less [original, $37 \mathrm{~s} ; 4422$ (PBS), $30 \mathrm{~s} ; 5533$ (PLA), $32 \mathrm{~s}$ ] as well as the $T_{1} \mathrm{C}$ of $\mathrm{CH}_{3}$ [original, $2.4 \mathrm{~s} ; 4422$ (PBS), $2.2 \mathrm{~s} ; 5533$ (PLA), $2.1 \mathrm{~s}$ ]. Moreover, the $T_{1} \mathrm{C}$ values of the PBS unit in PHA4422P (3) and the $T_{1} \mathrm{C}$ values of the PLA unit $\mathrm{CH}_{3}$ in PHA5533L (4) were slightly reduced by the copolymerization, compared with the original $T_{1} \mathrm{C}$ values. Since the copolymerization with either PBS or PLA decreased the crystallinity of the PHB unit (Figure 3), the reduction of the $T_{1} \mathrm{C}$ values of the PHB unit could be also explained by a change of $T_{1} \mathrm{C}$ relaxation due to the heterogeneity arising from the amorphous moiety. We will discuss the relationship of the heterogeneity with the compatibility of the copolymer components and molecular mobility later. 


\subsection{Spin-Lattice Relaxation Time in the Rotating Frame of Plasticized PHA Copolymers and Constituent Polymers}

The ${ }^{1} \mathrm{H}$ spin-lattice relaxation in the rotating frame $\left(T_{1 \rho} \mathrm{H}\right.$ relaxation) is promoted by molecular motions near the spin-locking frequency, which is much less than the Larmor frequency. That is, the ${ }^{1} \mathrm{H}$ spin-lattice relaxation time in the rotating frame $\left(T_{1} \rho \mathrm{H}\right)$ is affected more than the $T_{1} \mathrm{H}$ value by slower molecular motions, such as the main chain motion of polymers.

Figure 6 shows $T_{1 \rho} \mathrm{H}$ values of plasticized PHA copolymers and constituent polymers. The significant decreases of the $T_{1} \mathrm{H}$ values for PHB due to the copolymerization with PBS and PLA were also observed for the $T_{1 \rho} \mathrm{H}$ values. The original PHB (1) showed comparable $T_{1 \rho} \mathrm{H}$ values for each substituent as follows: $\mathrm{C}=\mathrm{O}, 30 \mathrm{~ms} ; \mathrm{CH}, 35 \mathrm{~ms} ; \mathrm{CH}_{2}, 38 \mathrm{~ms} ; \mathrm{CH}_{3}, 33 \mathrm{~ms}$. The $T_{1 \rho} \mathrm{H}$ values of the PHB unit were obviously reduced by the copolymerization with the biodegradable polyesters. Except for the $\mathrm{C}=\mathrm{O}$ group, the reduction ratios of $T_{1 \rho} \mathrm{H}$ values were larger in the copolymer with $\mathrm{PBS}$ [PHA4422P (3): 16-24 ms] than in the copolymer with PLA [PHA5533L (4): 24-33 ms]. Meanwhile, PBS (2) took lower $T_{1 \rho} \mathrm{H}$ values, such as $\mathrm{C}=\mathrm{O}(24 \mathrm{~ms}), \mathrm{OCH}_{2}(22 \mathrm{~ms}), \mathrm{C}(=\mathrm{O}) \mathrm{CH}_{2}(20 \mathrm{~ms}), \mathrm{CH}_{2}$ (12 ms). The $T_{1 \rho} \mathrm{H}$ values of PBS unit stayed almost unchanged for PHA4422P (3) (13-27 ms) while they decreased in PHA5533L (4) (6-17 ms). The $T_{1} \rho \mathrm{H}$ values of $\mathrm{CH}_{3}$ in PLA (5) also decreased with the copolymerization (PLA, 26 ms; PHA5533L, $11 \mathrm{~ms}$ ).

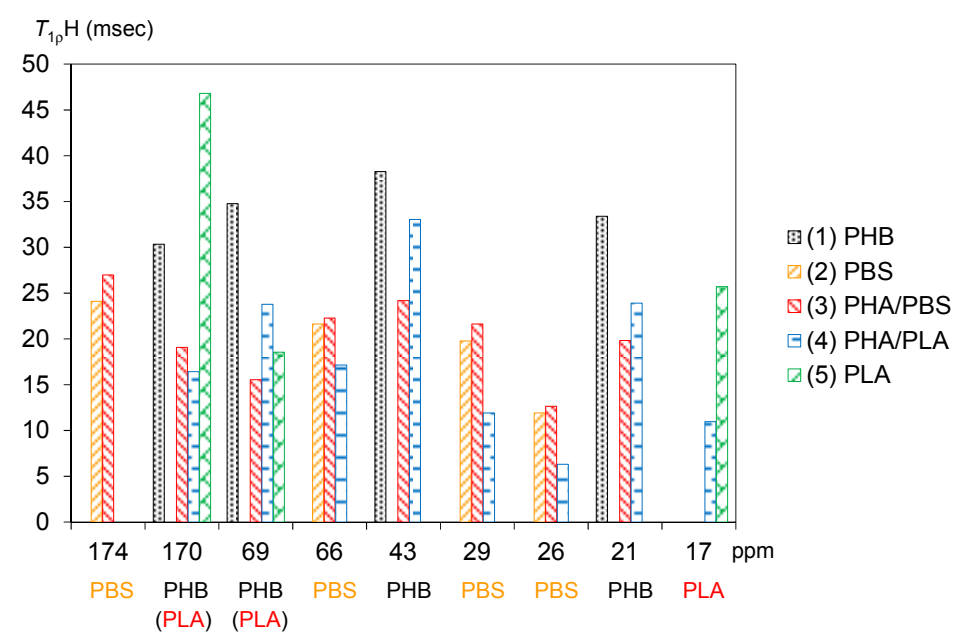

Figure 6. Changes of $T_{1 \rho} \mathrm{H}$ values with copolymerization. The horizontal axis shows the chemical shift of each signal appearing in the ${ }^{13} \mathrm{C} C P$-MAS NMR spectra while the vertical axis shows the corresponding $T_{1 \rho} \mathrm{H}$ value.

As shown above, since the spin-lattice relaxation times in the laboratory frame $\left(T_{1} \mathrm{H}\right.$ and $\left.T_{1} \mathrm{C}\right)$ showed a similar trend between PHA4422P (PBS) and PHA5533L (PLA), rapid molecular motions $(\mathrm{MHz})$ matched with the Larmor frequency in both plasticized PHA copolymers was enhanced by the plasticization. On the other hand, the spin-lattice relaxation time in the rotating frame $\left(T_{1 \rho} \mathrm{H}\right)$ decreased more in PHA4422P. Therefore, the plasticization with the flexible PBS enhanced slow molecular motions $(\mathrm{kHz})$ corresponding to the spin-locking frequency more than did PLA. We previously discussed the correlation of increase of the PST-MAS signals and $T_{1 \rho} \mathrm{H}$ values for phenol formaldehyde resin-impregnated soft wood [25]. Similar to this previous result, the increases of the ${ }^{13} \mathrm{C}$ PST-MAS NMR signals here could be explained by the enhancement of slow molecular motions $(\mathrm{kHz})$ due to the plasticization with PBS. We will discuss the increase of ${ }^{1} \mathrm{H}$ MAS NMR signals related to the slow molecular motion in the next subsection. 


\subsection{Changes of ${ }^{1} H$ MAS NMR with Rising Temperature}

Figure 7 shows variable temperature ${ }^{1} \mathrm{H}$ MAS NMR spectra of plasticized PHA copolymers and constituent polymers. Because of strong dipolar-dipolar interactions of ${ }^{1} \mathrm{H}$ nuclei with each other, the ${ }^{1} \mathrm{H}$ signals in the solid-state NMR appear as broad overlapped signals. The original PHB (1) showed only such signals, which changed little with increasing temperature; the $\mathrm{CH}_{3}$ signal sharpened and increased and the broader peaks in the $\mathrm{CH}$ and $\mathrm{CH}_{2}$ regions decreased at the same time. This showed that the molecular mobility of PHB (1) alone remained almost unchanged by the temperature rise. For the flexible PBS (2), however, every signal significantly sharpened and increased with increasing temperature, even though only very broad and weak peaks appeared at low temperatures $\left(-40^{\circ} \mathrm{C}\right)$. That is, the mobility of flexible PBS (2) was greatly affected by the temperature rise, resulting in a sharpened and larger ${ }^{1} \mathrm{H}$ MAS signals. Interestingly, the copolymerization of PHA with PBS [PHA4422P (3)] enlarged and sharpened the signals of not only the PBS unit but also the PHB unit. The rate of increase of the ${ }^{1} \mathrm{H}$ signals for both PHA and PBS units in PHA4422P (3) was greater than for PBS (2) alone; thus, the copolymerization of PHA with PBS increased the mobility of not only the PHA unit but also the PBS unit compared with the original polymers. Meanwhile, the ${ }^{1} \mathrm{H}$ signal intensity of rigid PLA (5) decreased with increasing temperature as seen for woody materials [26,27]. These ${ }^{1} \mathrm{H}$ signal decreases may occur due to sensitivity change of the detecting coil in the probe; now, we are still searching other reasons related to the magnetic relaxation. The plasticized PHA5533L (4) showed only the overlapped ${ }^{1} \mathrm{H}$ signal of PHB and PLA units, which simply changed in the same manner as each polymer alone, with no increase in signal or sharpness. According to the variable ${ }^{1} \mathrm{H}$ MAS NMR results, the flexibility of the polymer significantly enhanced slow molecular motions $(\mathrm{kHz})$ corresponding to the $T_{1 \rho} \mathrm{H}$ relaxation, resulting in sharp and large ${ }^{1} \mathrm{H}$ signals after plasticization with PBS. The slow molecular motion ( $\mathrm{kHz}$ order) corresponded to the motion of polymer chains, which was enhanced at temperatures over $-10^{\circ} \mathrm{C}$.

(1) PHB

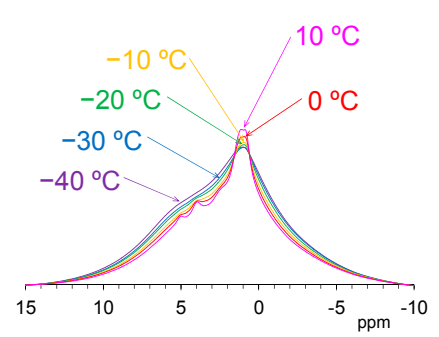

(4) PHA/PLA

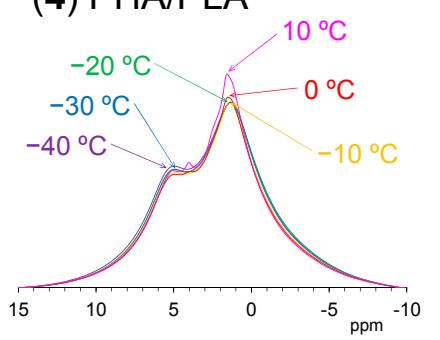

(2) PBS

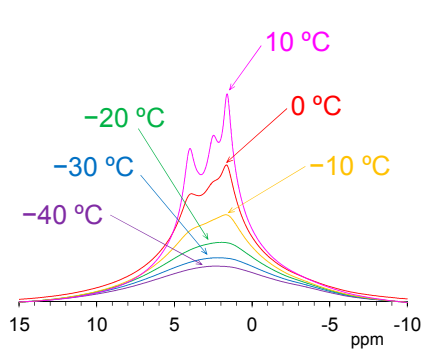

(5) PLA

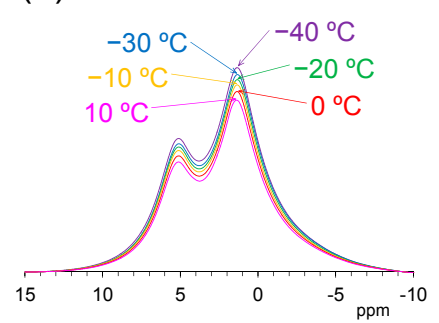

(3) PHA/PBS $\quad h^{10^{\circ} \mathrm{C}}$

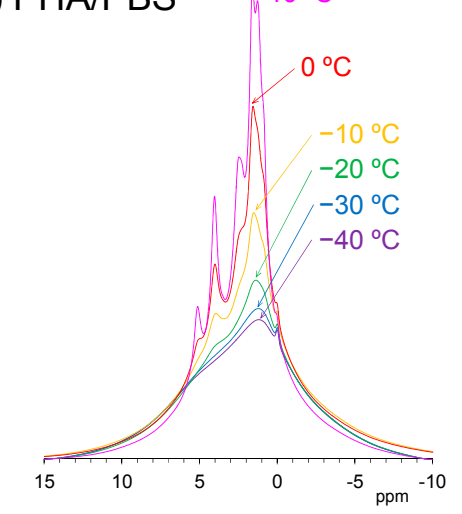

(1)

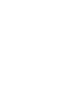




\subsection{Changes of Spin-Lattice Relaxation Times in the Laboratory Frame with Rising Temperature}

In order to investigate the rapid molecular motions $(\mathrm{MHz})$ that participated in the spin-lattice relaxation in the laboratory frame, rising temperature $T_{1} \mathrm{H}$ and $T_{1} \mathrm{C}$ measurements were performed in two temperature regions. The $T_{1} \mathrm{H}$ and $T_{1} \mathrm{C}$ changes due to the temperature rises are summarized in Figures 8 and 9 , respectively.

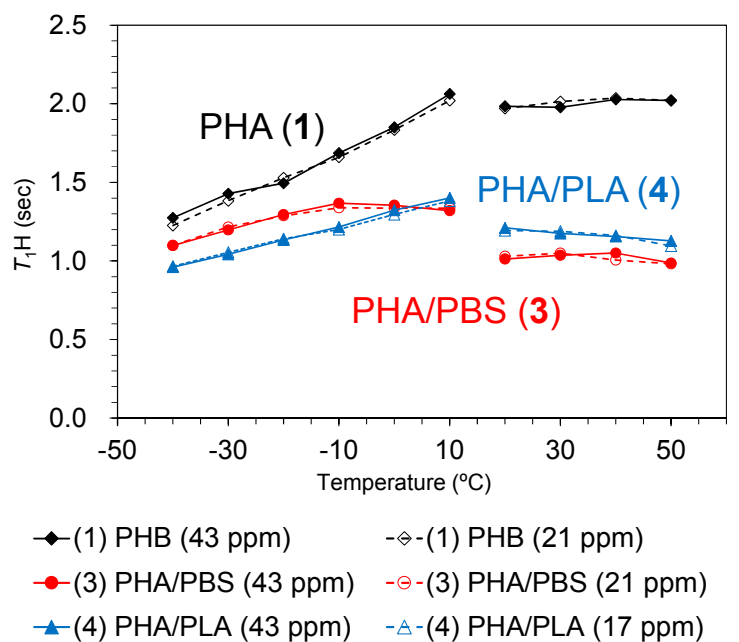

(a) PHA unit

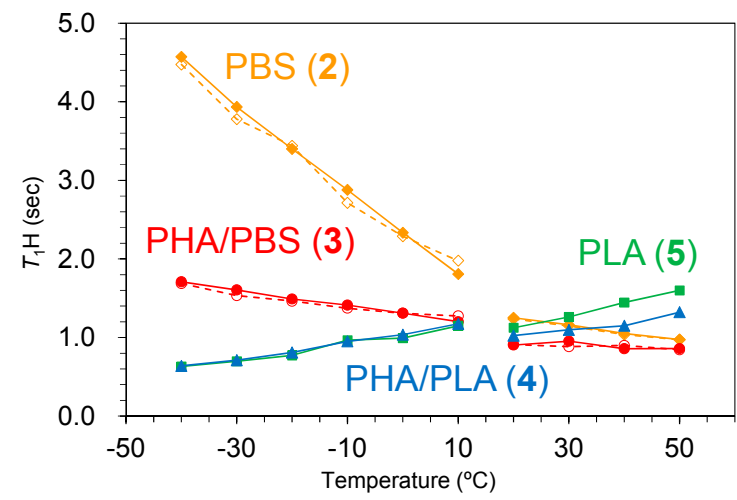

$\begin{array}{ll}-\diamond(2) \text { PBS (29 ppm) } & -\diamond-(2) \text { PBS (26 ppm) } \\ \rightarrow-(3) \text { PHA/PBS (29 ppm) } & -\ominus-(3) \text { PHA/PBS (26 ppm) } \\ \rightarrow-(5) \text { PLA (17 ppm) } & -\leftarrow \text { (4) PHA/PLA (17 ppm) }\end{array}$

(b) PBS/PLA unit

Figure 8. $T_{1} \mathrm{H}$ changes of PHA (a) and poly(butylene succinate)/poly(lactic acid) (PBS/PLA) units (b) in plasticized PHA copolymers with rising temperature. The temperature was increased from $40{ }^{\circ} \mathrm{C}$ to $-10{ }^{\circ} \mathrm{C}$ (low temperature side) and from $20{ }^{\circ} \mathrm{C}$ to $50{ }^{\circ} \mathrm{C}$ (high temperature side).
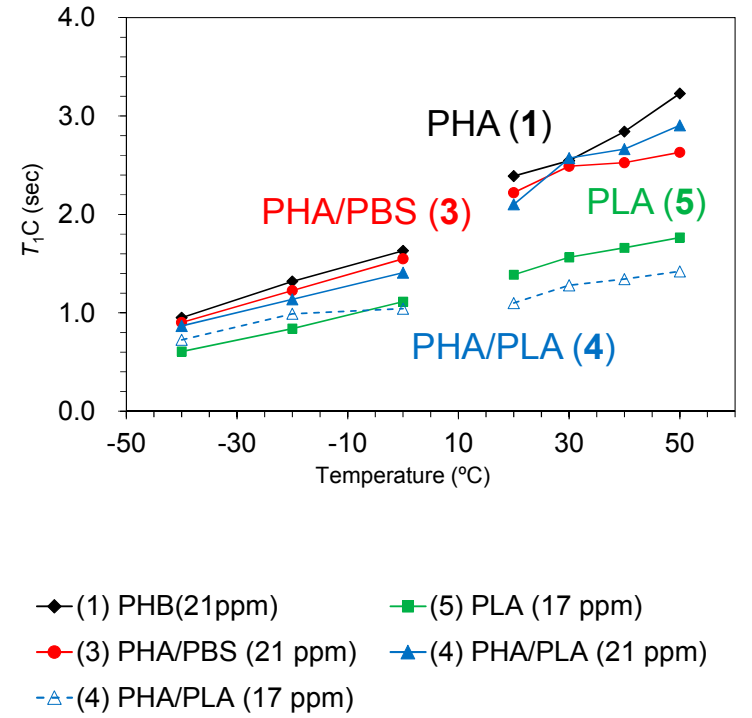

(a) $\mathrm{CH}_{3}$
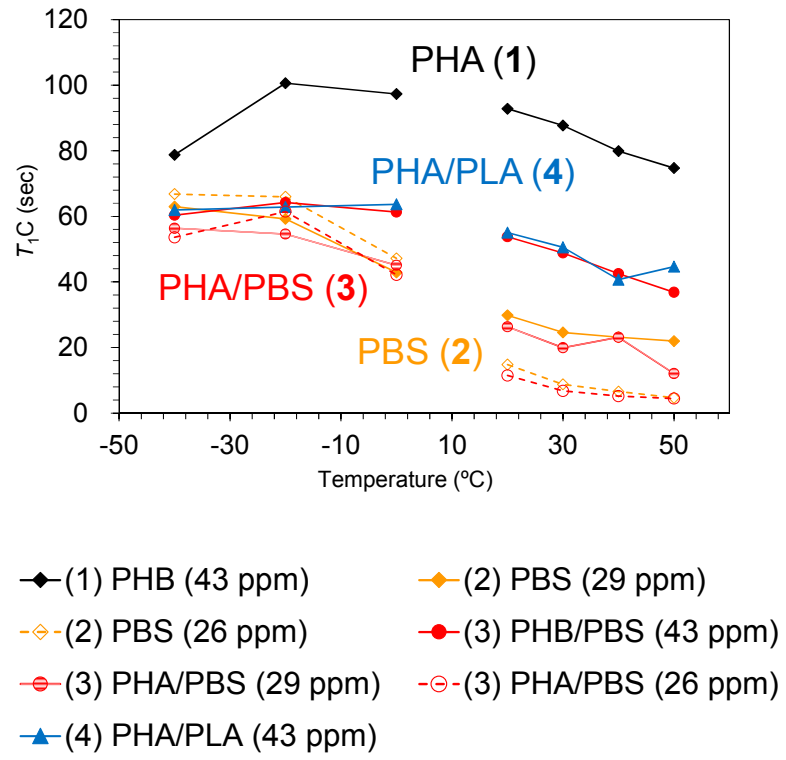

(b) $\mathrm{CH}_{2}$

Figure 9. $T_{1} \mathrm{C}$ changes of $\mathrm{CH}_{3}$ (a) and $\mathrm{CH}_{2}$ (b) groups in plasticized PHA copolymers with rising temperature. The temperature was increased from $40{ }^{\circ} \mathrm{C}$ to $0{ }^{\circ} \mathrm{C}$ (low-temperature side) and from $20^{\circ} \mathrm{C}$ to $50{ }^{\circ} \mathrm{C}$ (high-temperature side).

The change in trends of $T_{1} \mathrm{H}$ and $T_{1} \mathrm{C}$ values was closely related to the existence of $\mathrm{CH}_{3}$ groups. The $T_{1} \mathrm{H}$ values of PHB (1) (Figure 8a, black line) and PLA (5) (Figure 8b, green line), both of which had $\mathrm{CH}_{3}$ groups, increased with increasing temperature except for the high temperature region of 
PHB (1). In contrast, PBS (2) (Figure 8b, orange line), which had no $\mathrm{CH}_{3}$ group, decreased with increasing temperature; the rate of decrease was significantly faster in the low-temperature region. The different change trend that correlates with the existence of $\mathrm{CH}_{3}$ groups was also observed in the $T_{1} \mathrm{C}$ values. The $T_{1} \mathrm{C}$ values of $\mathrm{CH}_{3}$ groups increased monotonically with increasing temperature in both PHB (1) (black line) and PLA (5) (green line) up to $50{ }^{\circ} \mathrm{C}$ (Figure 9a). Conversely, a decrease with rising temperature was observed for the $T_{1} \mathrm{C}$ value of each substituent in PBS (Figure $9 \mathrm{~b}$, orange line). The $\mathrm{CH}_{2}$ group in PHB (43 ppm) has a very long $T_{1} \mathrm{C}$ value (over $80 \mathrm{~s}$ ), which increased in the low temperature and decreased in the high temperature regions (Figure $9 \mathrm{~b}$, black line). These trends of $T_{1}$ values showed that the rotation of $\mathrm{CH}_{3}$ in PHB and PLA had a lower correlation time $\left(\tau_{\mathrm{c}}\right)$ than molecular motions of $\mathrm{CH}_{2}$ in PHB and PBS.

Although the $T_{1} \mathrm{H}$ value of the PHA unit in PHA4422P (3) increased to $-10{ }^{\circ} \mathrm{C}$, it started to decrease over $-10^{\circ} \mathrm{C}$ (Figure 8a, red line). The $T_{1} \mathrm{H}$ value of PBS unit in PHA4422P (3) conversely decreased and the rate of decrease became smaller in the high-temperature region (Figure 8b, red line). As a result, the $T_{1} \mathrm{H}$ values of PHA and PBS units in PHA4422P (3) approached each other over $-10{ }^{\circ} \mathrm{C}$ and these approached the $T_{1} \mathrm{H}$ values of PHA and PBS units which maintained their relationship in the higher temperature region. The approached $T_{1} \mathrm{H}$ values are caused by the ${ }^{1} \mathrm{H}$ spin diffusion via the interface between PHB and PBS, which increases with improving polymer compatibility of PHA and PBS units above $-10{ }^{\circ} \mathrm{C}$. This interfacial ${ }^{1} \mathrm{H}$ spin diffusion possibly enhanced the $\mathrm{T}_{1} \mathrm{H}$ relaxation in the whole system of PHB/PBS copolymer. The improved compatibility for PHA4422P (3) also made ${ }^{1} \mathrm{H}$ MAS NMR signals sharper and larger at temperatures over $-10{ }^{\circ} \mathrm{C}$ (Figure 7). Although a $T_{1} \mathrm{H}$ reduction of the PHA unit was also observed in PHA5533L (4) (Figure 8a, blue line), no inflection points of the $T_{1} \mathrm{H}$ curve were observed in the low-temperature region and the ${ }^{1} \mathrm{H}$ MAS NMR spectra changed only slightly in PHA5533L (4). These results indicated that the polymer compatibility between PHA and PLA was less improved in PHA5533L (4) although the $T_{1} \mathrm{H}$ relaxation was enhanced by the heterogeneity.

The $T_{1} \mathrm{C}$ value of the $\mathrm{CH}_{2}$ groups in the plasticized PHA copolymers gave information about rapid molecular motions ( $\mathrm{MHz}$ order) of the polymer chain. In all temperature ranges, the PHB unit of the plasticized PHA copolymers has a low $T_{1} \mathrm{C}$ value, compared with the pre-plasticized PHB, although the PBS units had similar $T_{1} C$ values regardless of the plasticization. The heterogeneity that had arisen from the amorphous moiety also increased the molecular mobility of the PHB chain, which enhanced the $T_{1} \mathrm{C}$ relaxation to produce the lowered $T_{1} \mathrm{C}$ value of the PHB unit. Meanwhile, the $T_{1} \mathrm{C}$ value of $\mathrm{CH}_{3}$ groups in the plasticized PHA copolymers provides information on the local motion of $\mathrm{CH}_{3}$ closely related to the $T_{1} \mathrm{H}$ relaxation. The reduction of the $T_{1} \mathrm{C}$ value of $\mathrm{CH}_{3}$ groups due to copolymerization was limited, unlike the $T_{1} \mathrm{H}$ value. Thus, the change of $T_{1} \mathrm{H}$ was not caused by the molecular motion of $\mathrm{CH}_{3}$ groups, but by the interaction between constituent polymers.

In conclusion, $T_{1} \mathrm{H}$ values can act as an index of polymer compatibility due to plasticization, while $T_{1} \mathrm{C}$ values of $\mathrm{CH}_{2}$ groups can provide an index of rapid molecular motions of constituent polymers. Moreover, the $T_{1 \rho} \mathrm{H}$ values can index slow molecular motions of the polymer main chain, along with the ${ }^{1} \mathrm{H}$ and ${ }^{13} \mathrm{C}$ PST-MAS NMR spectra. Since copolymerization of PHA with PBS improved elongation and impact properties, the increase in slow molecular motions and compatibility of the PHA/PBS copolymer is possibly related to such polymer properties. Next, we are planning to study other biomass-based polymers to relate polymer properties to the indexes in solid-state NMR analytical methods proposed in the present study.

\section{Conclusions}

With the aim of extending the application of solid-state NMR to biomass-based polymers, two kinds of biodegradable polyesters, poly (butylene succinate) (PBS) and poly(lactic acid) (PLA), were examined for the plasticization of the biopolymers of no nutritional use, polyhydroxyalkanoates (PHA). Both biodegradable polyesters improved the thermal properties of PHA; the flexible PBS decreased the melting point of PHB while the rigid PLA added a glass transition point to PHB. 
Moreover, the biodegradable polyesters lowered the crystallinity of poly(3-hydroxybutyrate) (PHB). ${ }^{1} \mathrm{H}$ MAS NMR spectra at $-40{ }^{\circ} \mathrm{C}$ showed broad and overlapped signals for all polymers measured. With increasing temperature, the PHA/PBS copolymer showed larger and sharper ${ }^{1} \mathrm{H}$ MAS signals of the PHB unit while those of the PHA/PLA copolymer remained similarly broad to those of the original PHB. The ${ }^{13} \mathrm{C}$ PST-MAS signals of the PHB unit were increased by copolymerization with PBS, in addition to the ${ }^{1} \mathrm{H}$ MAS signals. Since ${ }^{1} \mathrm{H}$ spin-lattice relaxation in the rotating frame $\left(T_{1} \rho \mathrm{H}\right)$ was decreased more by the copolymerization with PBS than PLA, the addition of PBS increased the amplitudes of slow molecular motions ( $\mathrm{kHz}$ order) of the polymer chain related to the spin-locking frequency. Meanwhile, ${ }^{1} \mathrm{H}$ and ${ }^{13} \mathrm{C}$ spin-lattice relaxation times in the laboratory frame $\left(T_{1} \mathrm{H}\right.$ and $T_{1} \mathrm{C}$ ), which were reflected matching with rapid molecular motions ( $\mathrm{MHz}$ order), were reduced by copolymerization not only with PBS but also with PLA. In other words, the disordered PHB chain in the amorphous moiety due to the copolymerization improved polymer compatibility between PHB and the added polyester and amplified rapid molecular motions. The compatibility enhanced the $T_{1} \mathrm{H}$ relaxation such that the time reduced and approached the $T_{1} \mathrm{H}$ values of the plasticized PHA. The increased rapid molecular motions of the PHB substituent promoted the $T_{1} \mathrm{C}$ relaxation to shorten the $T_{1} \mathrm{C}$ value of $\mathrm{CH}_{2}$ in the plasticized PHA. Our present study makes it possible to use solid-state NMR parameters as the index of molecular mobility and polymer compatibility. Studies of production process and mechanical properties using other biomass-based polymers using the solid-state NMR parameters are currently in progress.

Author Contributions: Masakazu Nishida and Masahiro Nishida conceived and designed the experiments; Masakazu Nishida and Tomoko Tanaka performed the experiments; Masakazu Nishida and Tomoko Tanaka analyzed the data; Masakazu Nishida, Yoshio Hayakawa, and Masahiro Nishida contributed reagents/materials/analysis tools; Masakazu Nishida wrote the paper.

Acknowledgments: The authors wish to express special thanks to Nobuo Sobue, National Institute of Advanced Industrial Science and Technology, for help with the XRD operation.

Conflicts of Interest: The authors declare no conflict of interest.

\section{References}

1. Akaraonye, E.; Keshavarz, T.; Roy, I. Production of polyhydroxyalkanoates: The future green materials of choice. J. Chem. Technol. Biotechnol. 2010, 85, 732-743. [CrossRef]

2. Chen, G.-Q. A microbial polyhydroxyalkanoates (PHA) based bio- and material industry. Chem. Soc. Rev. 2009, 38, 2434-2446. [CrossRef] [PubMed]

3. Koller, M.; Maršálek, L.; Miranda de Sousa Dias, M.; Braunegg, G. Producing microbial polyhydroxyalkanoate (PHA) biopolyesters in a sustainable manner. New Biotechnol. 2017, 37, 24-38. [CrossRef] [PubMed]

4. Kourmentza, C.; Plácido, J.; Venetsaneas, N.; Burniol-Figols, A.; Varrone, C.; Gavala, H.N.; Reis, M.A.M. Recent advances and challenges towards sustainable polyhydroxyalkanoate (PHA) production. Bioengineering 2017, 4, 55. [CrossRef] [PubMed]

5. Laycock, B.; Halley, P.; Pratt, S.; Werker, A.; Lant, P. The chemomechanical properties of microbial polyhydroxyalkanoates. Prog. Polym. Sci. 2013, 38, 536-583. [CrossRef]

6. Li, Z.; Loh, X.J. Water soluble polyhydroxyalkanoates: Future materials for therapeutic applications. Chem. Soc. Rev. 2015, 44, 2865-2879. [CrossRef] [PubMed]

7. Mekonnen, T.; Mussone, P.; Khalil, H.; Bressler, D. Progress in bio-based plastics and plasticizing modifications. J. Mater. Chem. A 2013, 1, 13379-13398. [CrossRef]

8. Wang, L.; Zhu, W.; Wang, X.; Chen, X.; Chen, G.-Q.; Xu, K. Processability modifications of poly(3-hydroxybutyrate) by plasticizing, blending, and stabilizing. J. Appl. Polym. Sci. 2008, 107, 166-173. [CrossRef]

9. Audic, J.-L.; Lemiègre, L.; Corre, Y.-M. Thermal and mechanical properties of a polyhydroxyalkanoates plasticized with biobased epoxidized broccoli oil. J. Appl. Polym. Sci. 2014, 131, 39983. [CrossRef] 
10. Wei, L.; McDonald, A.G. Peroxide induced cross-linking by reactive melt processing of two biopolyesters: Poly(3-hydroxybutyrate) and poly(L-lactic acid) to improve their melting processability. J. Appl. Polym. Sci. 2015, 132, 41724. [CrossRef]

11. Ma, P.; Hristova-Bogaerds, D.G.; Lemstra, P.J.; Zhang, Y.; Wang, S. Toughening of PHBV/PBS and $\mathrm{PHB} / \mathrm{PBS}$ blends via in situ compatibilization using dicumyl peroxide as a free-radical grafting initiator. Macromol. Mater. Eng. 2012, 297, 402-410. [CrossRef]

12. Garcia-Garcia, D.; Ferri, J.M.; Boronat, T.; Lopez-Martinez, J.; Balart, R. Processing and characterization of binary poly(hydroxybutyrate) (PHB) and poly(caprolactone) (PCL) blends with improved impact properties. Polym. Bull. 2016, 73, 3333-3350. [CrossRef]

13. Pérez Amaro, L.; Chen, H.; Barghini, A.; Corti, A.; Chiellini, E. High performance compostable biocomposites based on bacterial polyesters suitable for injection molding and blow extrusion. Chem. Biochem. Eng. Q. 2015, 29, 261-274. [CrossRef]

14. Jost, V.; Kopitzky, R. Blending of polyhydroxybutyrate-co-valerate with polylactic acid for packaging applications-Reflections on miscibility and effects on the mechanical and barrier properties. Chem. Biochem. Eng. Q. 2015, 29, 221-246. [CrossRef]

15. Nishida, M.; Ogura, T.; Shinzawa, H.; Nishida, M.; Kanematsu, W. Tensile properties of polyhydroxyalkanoate/polycaprolactone blends studied by rheo-optical near-infrared (NIR) spectroscopy. J. Mol. Struct. 2016, 1124, 92-97. [CrossRef]

16. Morin, F.G.; Marchessault, R.H. Solid-state ${ }^{13} \mathrm{C}$ NMR study of the molecular dynamics in amorphous and crystalline poly( $\beta$-hydroxyalkanoates). Macromolecules 1992, 25, 576-581. [CrossRef]

17. Cao, A.; Asakawa, N.; Yoshie, N.; Inoue, Y. High-resolution solid-state ${ }^{13} \mathrm{C}$ n.m.r. study on phase structure of the compositionally fractionated bacterial copolyester poly(3-hydroxybutyric acid-co-3-hydroxypropionic acid)s. Polymer 1999, 40, 3309-3322. [CrossRef]

18. Zhang, L.; Tang, H.; Hou, G.; Shen, Y.; Deng, F. The domain structure and mobility of semi-crystalline poly(3-hydroxybutyrate) and poly(3-hydroxybutyrate-co-3-hydroxyvalerate): A solid-state NMR study. Polymer 2007, 48, 2928-2938. [CrossRef]

19. Wu, C.-S. Mechanical properties, biocompatibility, and biodegradation of cross-linked cellulose acetate-reinforced polyester composites. Carbohydr. Polym. 2014, 105, 41-48. [CrossRef] [PubMed]

20. Cavalcante, M.P.; Toledo, A.L.M.M.; Rodrigues, E.J.R.; Neto, R.P.C.; Tavares, M.I.B. Correlation between traditional techniques and TD-NMR to determine the morphology of PHB/PCL blends. Polym. Test. 2017, 58, 159-165. [CrossRef]

21. Baran, A.; Vrábel, P.; Olčák, D.; Chodák, I. Solid state ${ }^{13} \mathrm{C}$ NMR study of a plasticized PLA/PHB polymer blend. J. Appl. Polym. Sci. 2018, 135, 46296. [CrossRef]

22. Nishida, M.; Nishimura, Y.; Tanaka, T.; Oonishi, M.; Kanematsu, W. Solid state NMR analysis of poly(L-lactide) random copolymer with poly(e-caprolactone) and its reactive extrusion process. J. Appl. Polym. Sci. 2012, 123, 1865-1873. [CrossRef]

23. Nishida, M.; Tanaka, T.; Yamaguchi, T.; Suzuki, K.; Kanematsu, W. Intercalative polymerization of L-lactide with organically modified clay by a reactive extrusion method and instrumental analyses of the poly(lactic acid)/clay nanocomposites. J. Appl. Polym. Sci. 2012, 125, E681-E690. [CrossRef]

24. Nishida, M.; Tanaka, T.; Tanaka, T.; Hayakawa, Y. Nucleating and plasticization effects in drawn poly(lactic acid) fiber during accelerated weathering degradation. Polymers 2018, 10, 365. [CrossRef]

25. Nishida, M.; Tanaka, T.; Miki, T.; Hayakawa, Y.; Kanayama, K. Integrated analysis of solid-state NMR spectra and nuclear magnetic relaxation times for the phenol formaldehyde (PF) resin impregnation process into soft wood. RSC Adv. 2017, 7, 54532-54541. [CrossRef]

26. Nishida, M.; Tanaka, T.; Miki, T.; Hayakawa, Y.; Kanayama, K. Instrumental analyses of nanostructures and interactions with water molecules of biomass constituents of Japanese cypress. Cellulose 2017, 24, 5295-5312. [CrossRef]

27. Nishida, M.; Tanaka, T.; Miki, T.; Ito, T.; Kanayama, K. Instrumental analyses of nanostructures and interactions with bound water of superheated steam treated plant materials. Ind. Crop. Prod. 2018, 114, 1-13. [CrossRef]

28. Torchia, D.A. The Measurement of Proton-enhanced carbon-13 $T_{1}$ values by a method which suppresses artifacts. J. Magn. Reson. 1978, 30, 613-616. [CrossRef] 
29. Hu, D.; Chung, A.-L.; Wu, L.-P.; Zhang, X.; Wu, Q.; Chen, J.-C.; Chen, G.-Q. Biosynthesis and characterization of polyhydroxyalkanoate block copolymer P3HB-b-P4HB. Biomacromolecules 2011, 12, 3166-3173. [CrossRef] [PubMed]

30. Charlon, S.; Marais, S.; Dargent, E.; Soulestin, J.; Sclavons, M.; Follain, N. Structure-barrier property relationship of biodegradable poly(butylene succinate) and poly[(butylene succinate)-co-(butylene adipate)] nanocomposites: Influence of the rigid amorphous fraction. Phys. Chem. Chem. Phys. 2015, 17, 29918-29934. [CrossRef] [PubMed]

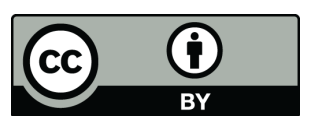

(c) 2018 by the authors. Licensee MDPI, Basel, Switzerland. This article is an open access article distributed under the terms and conditions of the Creative Commons Attribution (CC BY) license (http://creativecommons.org/licenses/by/4.0/). 